\title{
APLIKASI METODE RUNGE KUTTA ORDE EMPAT PADA PENYELESAIAN RANGKAIAN LISTRIK RLC
}

Application of Fourth Order Runge Kutta methods on Completion of the Electrical Circuit RLC

\author{
SAMSUL B. LOKLOMIN ${ }^{1}$, FRANCIS Y. RUMLAWANG ${ }^{2}$ \\ ${ }^{1}$ Alumni Jurusan Matematika Fakultas MIPA Universitas Pattimura \\ ${ }^{2}$ Staf Jurusan Matematika Fakultas MIPA Universitas Pattimura \\ Jl. Ir. M. Putuhena, Kampus Unpatti, Poka-Ambon \\ E-mail: ${ }^{2}$ rumlawang@ @staff.unpatti.ac.id
}

\begin{abstract}
ABSTRAK
Dalam penelitian ini akan ditentukan solusi penyelesaian persamaan diferensial orde kedua yang timbul dalam masalah rangkaian listrik RLC dengan menggunakan metode RungeKutta orde empat. Persamaan diferensial orde kedua dibentuk menjadi sistem persamaan orde pertama dan diselesaikan secara simultan. Hasilnya diperoleh solusi yang tingkat presisinya cukup tinggi jika dibandingkan dengan solusi analitiknya.
\end{abstract}

Kata kunci : Metode Runge-Kutta, Persamaan Diferensial, Rangkaian Listrik RLC.

\section{PENDAHULUAN}

Salah satu model matematika dalam fisika dan elektronika adalahmodelrangkaianlistrik. Rangkaian listrik adalah suatu kumpulan elemen atau komponen listrik yang saling dihubungkan dengan cara-cara tertentu dan paling sedikit mempunyai satu lintasan tertutup yang terdiri atas hambatan $R$, induktansi $L$, dan kapasitansi $C$.

Jika $R, L$ dan $C$ disusun secara seri dengan input tegangan, model matematikanya berbentuk persamaan diferensial linear ordedua. Persamaan matematika ini cukup panjang prosedurnya jika diselesaikan secara analitik oleh karena itu dilakukan pendekatan secara numerik.

Metode Numerik yang banyak dipakai dalam menyelesaikan persamaan diferensial adalah metode Range-Kutta hal ini dikarenakan metode ini mempunyai presisi yang cukup tinggi.

Dalam penelitian ini akan ditentukan solusi penyelesaian persamaan diferensial orde kedua yang timbul dalam masalah rangkaian listrik RLC dengan menggunakan metode Runge-Kutta orde empat dengan membentuk persamaan orde kedua menjadi sistem persamaan orde pertama dan diselesaikan secara simultan.

\section{TINJAUAN PUSTAKA}

Dalam [1] dan [2] dibahas mengenai penyelesaian persamaan diferensial biasa secara numerik dengan menggunakan metode Range-Kutta. Dibahas pula bagaimana menyelesaikan persamaan diferensial orde dua dengan mereduksinya menjadi dua persamaan diferensial orde satu yang dapat diselesaikan secara simultan, yang dikenal sebagai penyelesaian sistem persamaan diferensial.

Rahayu 2005 dalam [4] menggunakanMetode Range-Kutta untuk menyelesaikan persamaan pendulum, sedangkan Arifin 2011 dalam [3] menggunakan Metode Range-Kutta orde dua untuk menyelesaikan persamaan rangkaian listrik RLC.

Dalam [3] dan [5] rangkaian RLC adalah rangkaian listrik yang di dalamnya mengandung resistor, kapasitor, dan induktor yang saling terhubung satu sama lain secara paralel maupun seri. Dalam gambar 1. Diperlihatkan rangkaian RLC yang menghubungkan suatu resistor yang beresistansi $R$ (ohm), suatu induktor yang berinduktansi $L$ (henry), dan sebuah kapasitor yang berkapasitansi $C$ (farad) sebuah sumber gaya elektromotif $E(t)$ (volt) dengan $t$ adalah waktu. 


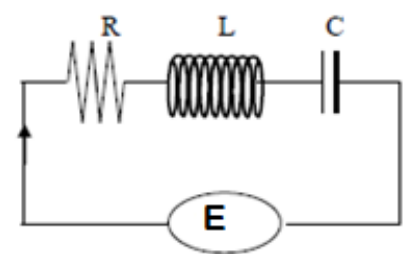

Gambar 1.Rangkaian Listrik RLC

\section{MetodeRunge-KuttaOrdeEmpat}

Bentuk Metode Runge-Kutta orde empat klasik untuk menyelesaikan persamaan diferensial adalah sebagai berikut:

$$
y_{n+1}=y_{n}+\frac{1}{6}\left(k_{1}+2 k_{2}+2 k_{3}+k_{4}\right)
$$

dengan

$$
\begin{aligned}
& k_{1}=h f\left(x_{n}, y_{n}\right) \\
& k_{2}=h f\left(x_{n}+\frac{1}{2} h, y_{n}+\frac{1}{2} k_{1}\right) \\
& k_{3}=h f\left(x_{n}+\frac{1}{2} h, y_{n}+\frac{1}{2} k_{2}\right) \\
& k_{4}=h f\left(x_{n}+h, y_{n}+k_{3}\right)
\end{aligned}
$$

Semua harga $k$ berhubungan secara rekursif. Artinya $k_{1}$ muncul dalam persamaan untuk $k_{2}$, yang muncul lagi pada persamaan $k_{3}$ danseterusnya. Dengan $y_{0}$ adalah initial value atau nilai awal.

\section{HASIL DAN PEMBAHASAN}

\section{Rangkaian Listrik Seri}

Rangkaian listrik seri adalah suatu rangkaian alat-alat listrik yang disusun berurutan tanpa adanya cabang. Langkah pertama dalam mencari solusi rangkaian ini adalah mencari persamaan rangkaian. Karena rangkaian mengandung $C$ dan $L$, maka ada dua peubah status, yaitu tegangan kapasitor dan arus induktor, yang dapat dipilih untuk digunakan dalam mencari persamaan rangkaian. Dalam mencari persamaan rangkaian terlebih dulu menggunakan tegangan kapasitor sebagai peubah rangkaian, kemudian melihat apa yang akan didapatkan jika arus induktor yang dipilih. Karena rangkaian adalah seri maka arus yang mengalir pada setiap beban adalah sama sedangkan tegangan pada setiap beban adalah berbeda. Dengan mengabaikan gaya gerak listrik induksi yang timbul pada resistor, besarnya arus listrik yang mengalir melalui resistor dapat ditentukan dengan hukum ohm persamaan:

$$
I=\frac{E_{R}}{R}
$$

dengan :

$I \quad$ : Arus listrik

$E_{R}:$ Tegangan Resistor

$R$ : Resistor

Sehingga diperoleh

$$
E_{R}=I R
$$

Apabila induktor mempunyai induktansi sebesar L, maka berdasar Hukum Lenz besar tegangan padabeban $\mathrm{L}$ dinyatakan dengan persamaan :

$$
E_{L}=\frac{d I}{d t}
$$

Sehingga hubungan resistor $(R)$, induktansi $(L)$, kapasitor $(C)$, dan Elektromotif $E(t)$ (Volt) adalah

$$
E_{L}+E_{R}+E_{C}=E(t)
$$

Maka diperoleh

$$
L \frac{d I}{d t}+I R+E_{c}=E(t)
$$

karena $I=I_{C}=C \frac{d E_{C}}{d t}$. maka persamaan (5) menjadi :

$$
L C \frac{d^{2} E_{c}}{d t^{2}}+R C \frac{d E_{c}}{d t}+E_{c}=E(t)
$$

Persamaan (6) di atas adalah persamaan diferensial orde kedua, yang merupakan diskripsi lengkap rangkaian, dengan tegangan kapasitor $E_{c}$ sebagai variabel terikat dan $t$ sebagai variabel bebas. Untuk memperoleh persamaan rangkaian dengan arus induktor $I$ sebagai peubah, kita manfaatkan hubungan arus tegangan kapasitor, yaitu

$$
I=I_{c}=C \frac{d E_{c}}{d t} \rightarrow E_{c}=\frac{1}{C} \int I d t
$$

Dengan mensubtitusi persamaan (7) ke (6) maka diperoleh

$$
L \frac{d I}{d t}+I R+\frac{1}{C} 0^{\prime} I d t=E(t)
$$

Dengan mendiferensialkan persamaan (8) terhadap I maka diperoleh

$$
L I^{\prime \prime}+R I^{\prime}+\frac{I}{C}=\frac{d E(t)}{d t}
$$

Persamaan (9) adalah persamaan diferensial orde dua dengan arus induktor $I$ sebagai variabel terikat dan $t$ sebagai variabel bebas. Persamaan (6) dan (9) sama bentuknya, hanya peubah sinyalnya yang berbeda. Hal ini berarti bahwa tegangan kapasitor ataupun arus induktor sebagai peubah akan memberikan persamaan rangkaian yang setara.

\section{Aplikasi Metode Runge-Kutta Orde Empat Pada Kasus Rangkaian Seri}

\section{Kasus 1:}

Sebuah rangkaian RLC dihubungkan secara seri memiliki $R=4$ Ohm, $C=1 / 5$ Farad, L=1 Henry, dan diberikan tegangan $E=12$ Volt. Pada saat $t=0$ kuat arus $I(0)=$ 
2 Ampere dan tegangan pada kapasitor $E_{c}(0)=5$ volt.

Tentukan tegangan kapasitor $E_{c}(t)$ untuk waktu $0 \leq t \leq$ 2 detik.

\section{Penyelesaian:}

Berdasarkan persamaaan (6) dapat dibentuk persamaan diferensial orde-2

$$
\frac{1}{5} \frac{d^{2} E_{c}}{d t^{2}}+\frac{4}{5} \frac{d E_{c}}{d t}+E_{c}=12
$$

Dengan $I(0)=2$ Ampere dan $E_{c}(0)=5$ volt. Karena $I=I_{c}=C . \frac{d E_{c}}{d t}$ maka $E_{c}^{\prime}(0)=10$. Sehingga rangkaian dapat dimodelkan ke persamaan diferensial tingkat dua.

Misalkan: $E_{c}=y$

$$
\frac{d^{2} E_{c}}{d t^{2}}+4 \frac{d E_{c}}{d t}+5 E_{c}=60
$$

Maka dapat ditulis:

$$
\frac{d^{2} y}{d t^{2}}+4 \frac{d y}{d t}+5 y-60=0
$$

Karena persamaan diferensial biasa berorde- 2 jadi di ubah menjadi persamaan diferensial orde-1.

$\begin{array}{ll}\text { Misal: } & \frac{d y}{d t}=y^{\prime}=z \\ & \frac{d^{2} y}{d t^{2}}=y^{\prime \prime}=z^{\prime}\end{array}$

diperoleh:

$$
\begin{array}{r}
y^{\prime \prime}+4 y^{\prime}+5 y-60=0 \\
z^{\prime}=-4 z-5 y+60
\end{array}
$$

Sehingga diperoleh 2 persamaan baru yang masingmasing orde pertama:

$$
y^{\prime}=z \text { dan } z^{\prime}=60-5 y-4 z
$$

Dengan $E_{c}(0)=y(0)=5$ dan $E_{c}^{\prime}(0)=y^{\prime}(0)=z(0)=$ 10

Penyelesaian sistem persamaan diferensial (11) dapat dilakukan dengan mengaplikasikan metode RangeKutta pada kedua persamaan tersebut (dapat dilihat dalam [2]).

Perhitungan dengan metode Runge-Kutta Orde 4 untuk iterasi ke-1, dengan $t_{0}=0 ; y_{0}=5 ; z_{0}=10$ adalah sebagai berikut:

$$
\begin{aligned}
k_{1} & =h f\left(t_{0}, y_{0}, z_{0}\right) \\
& =0,1 f(0,5,10) \\
& =0,1(10) \\
& =1 \\
l_{1} & =h f\left(t_{0}, y_{0}, z_{0}\right) \\
& =0,1 f(0,5,10) \\
& =0,1(60-5(5)-4(10)) \\
& =0,1(-5) \\
& =-0,5 \\
k_{2} & =h f\left(t_{0}+\frac{1}{2} h, y_{0}+\frac{1}{2} k_{1}, z_{0}+\frac{1}{2} l_{1}\right) \\
& =0,1 f\left(0+\frac{1}{2}(0.1), 5+\frac{1}{2}(1), 10+\frac{1}{2}(-0.5)\right) \\
& =0,1 f(0,05 ; 5,5, ; 9,75)
\end{aligned}
$$

$=0,1(9,75)$

$=0,975$

$l_{2}=h f\left(t_{0}+\frac{1}{2} h, y_{0}+\frac{1}{2} k_{1}, z_{0}+\frac{1}{2} l_{1}\right)$

$=0,1 f\left(0+\frac{1}{2}(0,1), 5+\frac{1}{2}(1), 10+\frac{1}{2}(-0,5)\right)$

$=0,1 f(0,05 ; 5,5 ; 9,75)$

$=0,1(60-5(5,5)-4(9,75))$

$=0,1(-6,5)$

$=-0,65$

$k_{3}=h f\left(t_{0}+\frac{1}{2} h, y_{0}+\frac{1}{2} k_{2}, z_{0}+\frac{1}{2} l_{2}\right)$

$=0.1 f\left(0+\frac{1}{2}(0,1), 5+\frac{1}{2}(0,975), 10+\frac{1}{2}(-0,65)\right)$

$=0,1 f(0,05, ; 5,4875 ; 9,675)$

$=0,1(9,675)$

$=0,9675$

$l_{3}=h f\left(t_{0}+\frac{1}{2} h, y_{0}+\frac{1}{2} k_{2}, z_{0}+\frac{1}{2} l_{2}\right)$

$=0,1 f\left(0+\frac{1}{2}(0,1), 5+\frac{1}{2}(0,975), 10+\frac{1}{2}(-0,65)\right)$

$=0,1 f(0,05 ; 5,4875 ; 9,675)$

$=0,1(60-5(5,4875)-4(9,675))$

$=0,1(-6,1375)$

$=-0,61375$

$k_{4}=h f\left(t_{0}+h, y_{0}+k_{3}, z_{0}+l_{3}\right)$

$=0,1(0+0,1 ; 5+0,9675 ; 10-0,61375)$

$=0,1(0,1 ; 5,9675 ; 9,38625)$

$=0,1(9,38625)$

$=0,938625$

$l_{4}=h f\left(t_{0}+h, y_{0}+k_{3}, z_{0}+l_{3}\right)$

$=0,1(0+0,1 ; 5+0.963 ; 10+(-0,601375))$

$=0,1(0,1 ; 5,9675 ; 9,38625)$

$=0,1(60-5(5,9675)-4(9,38625))$

$=0,1(-7,3825)$

$=-0,73825$

Rumus iterasi ke-1 metode Runge-Kutta Orde 4:

$$
\begin{gathered}
y_{1}=y_{0}+\frac{1}{6}\left(k_{1}+2 k_{2}+2 k_{3}+k_{4}\right) \\
=5+\frac{1}{6}(1+2(0,975)+2(0,9675)+0,938625) \\
=5,970604167 \\
z_{1}=z_{0}+\frac{1}{6}\left(l_{1}+2 l_{2}+2 l_{3}+l_{4}\right) \\
=10+\frac{1}{6}(-0,5+2(-0,65)+2(-0,61375)-0,73825) \\
=9,372375
\end{gathered}
$$

Selanjutnya dilakukan perhitungan dengan metode Runge-Kutta Orde 4 untuk iterasi ke-2, dengan $t_{1}=$ 0,$1 ; y_{1}=5,9706 ; z_{1}=9,3724$ sehingga diperoleh nilai $y_{2}=6,868611$ dan $z_{2}=8,5671$.

Perhitungan dilakukan sampai iterasi ke-20 untuk memperoleh nilai $y_{20}$ dan $z_{20}$.

Solusi dari persamaan (10) adalah nilai $y_{0}$ sampai $y_{20}$ yang merupakan nilai $E_{c}(t)$ dimana $0 \leq t \leq$ 2 dengan langkah 0.1 
Solusi analitik persamaan (10) adalah.

$$
y(t)=E_{c}(t)=12-4 e^{-2 t} \sin (t)-7 e^{-2 t} \cos (t)
$$

Perbandingan solusi persamaan (10) secara numerik dan analitik serta galat dari kedua solusi diberikan oleh tabel berikut.

Tabel.1 Nilai Pendekatan Metode Runge-Kutta orde 4

\begin{tabular}{|c|c|c|c|c|}
\hline Iterasi & $\mathrm{t}$ & $\begin{array}{c}\text { Solusi } \\
\text { Analitik }\end{array}$ & $\begin{array}{c}\text { Solusi } \\
\text { Numerik }\end{array}$ & Galat \\
\hline & 0 & 5 & 5 & 0 \\
\hline 1. & 0.1 & 6.26318 & 5.970604 & 0.292576 \\
\hline 2. & 0.2 & 7.29843 & 6.868658 & 0.429772 \\
\hline 3. & 0.3 & 8.14688 & 7.681225 & 0.465655 \\
\hline 4. & 0.4 & 8.84223 & 8.403141 & 0.439089 \\
\hline 5. & 0.5 & 9.4121 & 9.0368 & 0.3753 \\
\hline 6. & 0.6 & 9.85461 & 9.5832 & 0.27141 \\
\hline 7. & 0.7 & 10.26189 & 10.049 & 0.21289 \\
\hline 8. & 0.8 & 10.57559 & 10.441 & 0.13459 \\
\hline 9. & 0.9 & 10.83267 & 10.767 & 0.06567 \\
\hline 10. & 1 & 11.04335 & 11.037 & 0.00635 \\
\hline 11. & 1.1 & 11.21601 & 11.257 & -0.04099 \\
\hline 12. & 1.2 & 11.35751 & 11.436 & -0.07849 \\
\hline 13. & 1.3 & 11.47348 & 11.578 & -0.10452 \\
\hline 14. & 1.4 & 11.56851 & 11.691 & -0.12249 \\
\hline 15. & 1.5 & 11.64639 & 11.779 & -0.13261 \\
\hline 16. & 1.6 & 11.71022 & 11.848 & -0.13778 \\
\hline 17. & 1.7 & 11.76253 & 11.9 & -0.13747 \\
\hline 18. & 1.8 & 11.80534 & 11.939 & -0.13366 \\
\hline 19. & 1.9 & 11.84052 & 11.967 & -0.12648 \\
\hline 20. & 2 & 11.8693 & 11.988 & -0.1187 \\
\hline
\end{tabular}

Secara grafik perbandingan solusi persamaan (10) secara numerik dan analitik dapat dilihat sebagai berikut

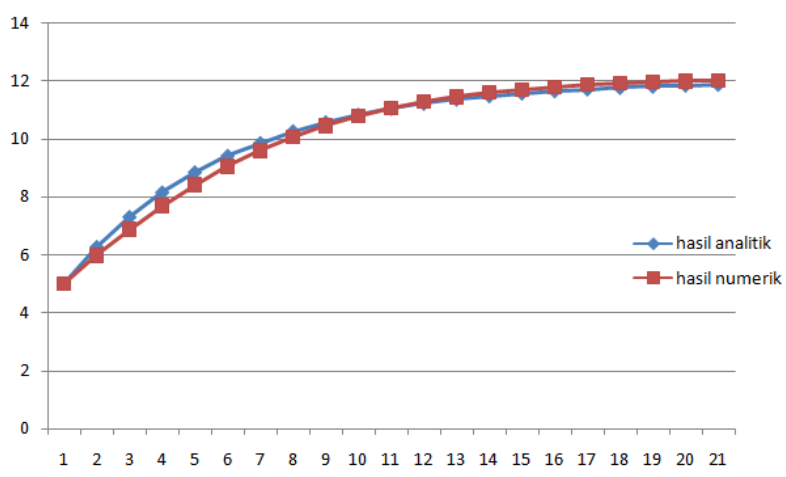

Grafik 1.Solusi analitik dan solusi numerik

\section{Kasus 2:}

Sebuah rangkaian listrik RLC yang terdiri dari resistor, kapasitor dan induktor dengan elemen-elemen $R=4 \Omega$,
$C=1 / 3$ Farad, L=1 Henry disusun secara seri dan diberikan tegangan $E=10$ Volt. Pada saat $t=0$ kuat arus $I(0)=2$ Ampere dan tegangan pada kapasitor $E_{c}(0)=$ 6 volt. Tentukan nilai $E_{c}(t)$ untuk waktu $0 \leq t \leq 1$ detik.

\section{Penyelesaian :}

Berdasarkan persamaaan (4.25) dapat dibentuk persamaan diferensial orde-2

$$
\frac{1}{3} \frac{d^{2} E_{c}}{d t^{2}}+\frac{4}{3} \frac{d E_{c}}{d t}+E_{c}=10
$$

Dengan $I(0)=2$ Ampere dan $E_{c}(0)=6$ Volt. Karena $I=I_{c}=C \cdot \frac{d E_{c}}{d t}$ maka $E_{c}{ }_{c}(0)=12$. Sehingga rangkaian dapat dimodelkan kepersamaan diferensial tingkat dua.

Misalkan $: E_{c}=y$

$$
\frac{d^{2} E_{c}}{d t^{2}}+4 \frac{d E_{c}}{d t}+3 E_{c}=30
$$

Maka

$$
\frac{d^{2} y}{d t^{2}}+4 \frac{d y}{d t}+3 y-30=0
$$

Untuk memperoleh solusi dengan pendekatan numerik diperlukan manipulasi persamaan diferensial orde dua kepersamaan diferensial orde pertama.

$\begin{array}{ll}\text { Misal: } & \frac{d y}{d t}=y^{\prime}=z \\ & \frac{d^{2} y}{d t^{2}}=y^{\prime \prime}=z^{\prime}\end{array}$

Jadi dapat ditulis :

$$
\begin{array}{r}
y^{\prime \prime}+4 y^{\prime}+3 y-30=0 \\
z^{\prime}=-4 z-3 y+30
\end{array}
$$

Sehingga diperoleh 2 persamaan orde pertama

$y^{\prime}=z$

$z^{\prime}=30-3 y-4 z$

Dengan $E_{c}(0)=y(0)=6$ dan $E_{c}^{\prime}(0)=y^{\prime}(0)=z(0)=$ 12 dengan $\mathrm{h}=0.1$

Tabel 2. Perbandingan Solusi Numerik dan Analitik kasus

\begin{tabular}{|c|c|r|r|r|}
\hline \multicolumn{1}{|c|}{ Iterasi } & \multicolumn{1}{c|}{$\mathrm{t}$} & $\begin{array}{c}\text { Solusi } \\
\text { Analitik }\end{array}$ & \multicolumn{1}{c|}{$\begin{array}{c}\text { Solusi } \\
\text { Numerik }\end{array}$} & \multicolumn{1}{l|}{ Galat } \\
\hline 1 & \multicolumn{1}{c|}{0} & 6 & 6 & 0 \\
\hline 2 & 0.1 & 6.87271 & 7.03665 & -0.16394 \\
\hline 3 & 0.2 & 7.53483 & 7.8046392 & -0.2698092 \\
\hline 4 & 0.3 & 8.039474 & 8.3735944 & -0.3341204 \\
\hline 5 & 0.4 & 8.42609 & 8.795098 & -0.369008 \\
\hline 6 & 0.5 & 8.72408 & 9.107363 & -0.383283 \\
\hline 7 & 0.6 & 8.95529 & 9.338701 & -0.383411 \\
\hline 8 & 0.7 & 9.13604 & 9.510085 & -0.374045 \\
\hline 9 & 0.8 & 9.27852 & 9.637053 & -0.358533 \\
\hline 10 & 0.9 & 9.391814 & 9.8008 & -0.408986 \\
\hline 11 & 1 & 9.48276 & 9.852425 & -0.369665 \\
\hline
\end{tabular}

Dengan melakukan perhitungandengan cara yang sama dengan pada kasus 1 dan dengan 
membandingkannya dengan solusi analitik persamaan (12) yang berbentuk

$$
E_{c}=10-e^{-t}-3 e^{-3 t}
$$

Perbandingan solusi numerik dan analitik persamaan (12) dapat dilihat dalam tabel 2.

Secara grafik perbandingan solusi persamaan (12) secara numerik dan analitik dapat dilihat sebagai berikut

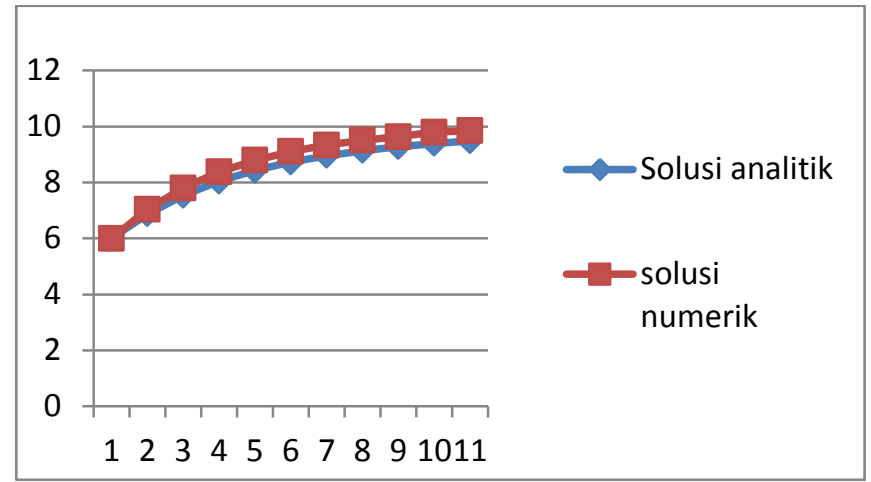

Grafik 2.Solusi analitik dan solusi numerik

\section{KESIMPULAN}

Dalam penyelesaian persamaan diferensial pada persamaan rangkaian listrik RLC secara numerik, persamaan diferensial orde- 2 diubah ke sistem persamaan orde pertama untuk memudahkan proses perhitungan.

Metode Runge-Kutta orde empat yang digunakan untuk penyelesaian rangkaian listrik RLC diaplikasikan pada sistem persamaan diferensial orde pertama secara simultan. Hasilnya dapat dilihat dalam kasus 1 ataupun kasus 2, jika dibandingakan dengan solusi analitiknya diperoleh nilai galat yang relatif kecil.

\section{DAFTAR PUSTAKA}

[1] Chapra C. Steven \& Canale P. Raymond. (1991). Metode Numerik Untuk Teknik Dengan Penerapan Pada Komputer, Universitas Indonesia, Jakarta.

[2] John H. Mathews \& Kurtis D. Fink. 1999. Numerical Methods Using Matlab $3^{\text {rd }}$ Ed. Prentice Hall Upper Saddle River NJ 07458

[3] Mizwar Arifin, Tulus. 2011. Metode Runge-Kutta Ordo-2 untuk penyelesaian rangkaian listrik $R L C$. Jurnal. Medan, Indonesia: Universitas Sumatera Utara.

[4] Puji Utami Rahayu. 2005. Metode Runge-Kutta Untuk Solusi Persamaan Pendulum. Skripsi Jurusan Matematika Universitas Negeri Semarang.

[5] Widagda, IGA. 2006. Fisika Komputasi. Fisika FMIPA UNUD : Bali 
